\title{
Profit Based Unit Commitment of Thermal Units with Renewable Energy and Electric Vehicles in Power Market
}

\author{
S. F. Syed Vasiyullah ${ }^{1} \oplus$. S. G. Bharathidasan ${ }^{2}$
}

Received: 29 October 2019 / Revised: 26 March 2020 / Accepted: 5 October 2020 / Published online: 21 October 2020

(C) The Author(s) 2020

\begin{abstract}
In restructured power system, Generation Companies (GENCOs) has an opportunity to sell power and reserve in power market to earn profit by market clearing process. Defining unit commitment problem in a competitive environment to maximize the profit of GENCOs while satisfying all the network constraints is called Profit Based Unit Commitment problem (PBUC). The main contribution of this paper is modeling and inclusion of Market Clearing Price (MCP) in PBUC problem. In Day market, $\mathrm{MCP}$ is determined by market operator which provides maximum social welfare for both GENCOs and Consumers.On other hand this paper proposes a novel combination of solution methodology: Improved Pre-prepared power demand (IPPD) table and Analytical Hierarchy method (AHP) for solving the optimal day ahead scheduling problem as an another contribution. In this method, the status of unit commitment is obtained by IPPD table and AHP provides an optimal solution to PBUC problem. Minimizing total operating cost of thermal units to provide maximum profit to GENCOs is called an optimal day ahead scheduling problem. Also it will be more realistic to redefine this problem to include multiple distributed resources and Electric vehicles with energy storage. Because of any uncertainties or fluctuation of renewable energy resources (RESs), Electric vehicles (EV) can be used as load, energy sources and energy storage. This would reduce cost, emission and to improve system power quality and reliability. So output power of solar $\left(\mathrm{P}_{\mathrm{S}}\right)$, wind output power $\left(\mathrm{P}_{\mathrm{W}}\right)$ and Electric Vehicles power $\left(\mathrm{P}_{\mathrm{EV}}\right)$ are modeled and included into day ahead scheduling problem. The proposed methodology is tested on a standard thermal unit system with or without RESs and EVs. Cost and emission reduction in a smart grid by maximum utilization of EVs and RESs are presented in this literature. It is indicated that the proposed method provides maximum profit to GENCOs when compared to other methodologies such as Memory Management Algorithm, Improved Particle Swarm Optimization (PSO), Muller method, Gravitational search algorithm etc.
\end{abstract}

Keywords Generation companies (GENCOs) - Improved pre-prepared demand (IPPD) table · Analytical hierarchy process (AHP) solar output power $\left(\mathrm{p}_{\mathrm{S}}\right) \cdot$ Wind output power $\left(\mathrm{p}_{\mathrm{W}}\right) \cdot$ Electric vehicles power $\left(\mathrm{p}_{\mathrm{EV}}\right)$

\begin{tabular}{|c|c|}
\hline \multicolumn{2}{|c|}{ Abbreviations } \\
\hline$P_{\mathrm{gen}}^{(i, t)}$ & $\begin{array}{l}\text { Power generation of the ith thermal units (MW) } \\
\text { at time } \mathrm{t}\end{array}$ \\
\hline$P_{s}^{t}$ & Solar power generation (MW) at hour $\mathrm{t}$ \\
\hline$P^{s}$ & Wind power generation (MW) at hour $\mathrm{t}$ \\
\hline$P_{E V}^{w}$ & Electric vehicle power (MW) at hour $\mathrm{t}$ \\
\hline$P D^{(t)}$ & Power demand (MW) at hour $\mathrm{t}$ \\
\hline
\end{tabular}

S. F. Syed Vasiyullah vasipse@gmail.com

S. G. Bharathidasan bharathi@svce.ac.in

1 AMSCE, Chennai, India

2 SVCE, Sriperumbudur, India

$\begin{array}{ll}P_{\text {gen }}^{\max (i, t)} & \begin{array}{l}\text { Maximum generation (MW) limit of generator i } \\ \text { at hour t }\end{array} \\ P_{\text {gen }}^{\min (i, t)} & \begin{array}{l}\text { Minimum generation (MW) limit of generator i } \\ \text { at hour t }\end{array} \\ P_{\text {res }}^{(i, t)} & \text { Generation of reserve power (MW) at hour t } \\ S^{(i, t)} & \text { Turn on/off status of generating unit i at hour t } \\ S R^{(t)} & \text { Spinning reserve (MW) at hour t } \\ M_{u p_{i}} & \text { Minimum up time of generator i (Hours) } \\ M_{d o w n} & \text { Minimum down time of generator i (Hours) } \\ i & \text { Number of generating units } \\ t & \text { Time period in hours } \\ A & \text { Albert Betz constant } \\ \nu & \text { Wind speed (m/s) at hour t } \\ R & \text { Radius of the wind turbine rotor in meters } \\ \rho & \text { Air density } \\ \eta & \text { Efficiency factor }\end{array}$




\begin{tabular}{|c|c|}
\hline$\xi_{P V}$ & PV module efficiency in \% \\
\hline$A_{P V}$ & Area of the PV module in $\mathrm{m}^{2}$ \\
\hline G & Solar irradiation in $\mathrm{W} / \mathrm{m}^{2}$ at hour $\mathrm{t}$ \\
\hline$\xi$ & Battery efficiency \\
\hline$P v$ & Average vehicle battery capacity \\
\hline$N_{E V 2 G}$ & Number of electric vehicle \\
\hline$T R C$ & Total revenue cost $(\$)$ \\
\hline TOC & Total operating cost $(\$)$. \\
\hline$E M R$ & Energy market revenue (\$) \\
\hline$R M R$ & Reserve market revenue $(\$)$ \\
\hline$F\left(P_{\mathrm{gen}}^{(i, t)}\right)$ & Fuel cost function of ith generating unit \\
\hline$F\left(P_{\mathrm{res}}^{(i, t)}\right)$ & $\begin{array}{l}\text { Fuel cost function of reserve in ith generating } \\
\text { unit }\end{array}$ \\
\hline$r$ & $\begin{array}{l}\text { Probability for that reserve to be called and } \\
\text { Generated at hour } t\end{array}$ \\
\hline$M C P^{(t)}$ & Market clearing price for power $(\$)$ at hour $\mathrm{t}$ \\
\hline$M C R^{(t)}$ & Market clearing price for reserve (\$) at hour $\mathrm{t}$ \\
\hline$S U^{(t)}$ & Startup cost $(\$)$ \\
\hline$a_{i}, b_{i}, c_{i}$ & $\begin{array}{l}\text { Fuel coefficients of the ith thermal generat- } \\
\text { ing unit in }(\$ / \mathrm{h}),(\$ / \mathrm{MWh}) \text { and }\left(\$ / \mathrm{MW}^{2} \mathrm{~h}\right) \\
\text { respectively }\end{array}$ \\
\hline$\alpha_{i}, \beta_{i} \gamma_{i}$ & Emission coefficients of thermal units in tons \\
\hline
\end{tabular}

\section{Introduction}

In recent times, the harmful gas from burning fossil fuel causes diseases for humans worldwide [1]. Even though many countries do not have domestic fossil sources [2], yet $85 \%$ of nations in the world consume fossil fuel based energy [3]. As fossil fuel are finite, not renewable and have the high risk of totally running out by the turn of next century [4], worldwide nations are desperate to reduce dependency on fossil based fuels [5]. In order to ease the environment and energy crisis, there has been an increasing interest in Electric Vehicles and over a past decade, there is a dramatic increase in EVs production up to $1500 \%$ [6]. Electric vehicles consume power from the grid to charge the batteries in the vehicle $[7,8]$ and the energy stored in the batteries can be also used to supply the grid. The power from Electric vehicles to grid can efficiently increase the load profile of electric power system with optimal scheduling of charging and discharging behavior which reduces the total running cost and emission [9].

In addition with EVs, the uses of Renewable energy reduce the operating Cost of Generating Companies and contribute to countries' economy [10]. Renewable energy resources mainly solar and wind play a most significant role in recent researches and due to the low electricity generation price and positive effect on environment [11, 12].

In deregulated environment, Generation Companies (GENCOs) are an entity with own generation resources and participate in the market with sole objective of maximizing the expected profit subjected to system and generators constraints [13]. GENCOs offer their services to energy and reserve markets depending upon the generator availability and this is referred as Profit Based Unit Commitment (PBUC).

This PBUC problem determines how much energy and reserve should be offered in deregulated power market to achieve the maximum profit. Here the problem of Profit Based Unit Commitment has two sub-problems: Initially the status and output powers of committed units are to be determined and then the determination of optimal bidding strategy is done to maximize the profit of the GENCOs.

Earlier, the PBUC problems were solved by various conventional methods such as Lagrangian Relaxation (LR) method [14], Priority List (PL) method [14] and Dynamic Programming (DP) method [15]. LR method provides fast solution but suffers from numerical divergence problem and PL method provides high speed of convergence but it leads to high operating cost for large scale problems. DP method can solve large scale problems but its complexity increases with increase in number of constraints. Also a hybrid Evolutionary Game theory has been proposed for optimal bidding of GENCOs in Energy and Ancillary services Markets [16]. In [17], a new genetic algorithm has been proposed to determine an optimal bidding strategy for GENCOs in Day Ahead market and to maximize the profit of GENCOs. In [18], Gravitational search algorithm (GSA) is a recent development which is used to solve reactive power dispatch problem. GSA has good convergence characteristics and less number of parameters.

However GSA convergence speed slows down in the large search space and it is easy to fall into local optimum solution. In [19], Particle Swarm Optimization (PSO) algorithm has been used to determine an optimal unit commitment schedule with all constraints to be met. But it has a low convergence rate in the iterative process and it cannot work out the problem of scattering.

It is evident that many existing methods have certain limitation in providing the solution within considerable computational time. Therefore in this work, improved pre-prepared power demand (IPPD) table based solution technique has been proposed. The IPPD table is constructed using system generation limits and fuel cost co-efficient to solve PBUC Problem [20].This approach gives the units to be committed for the specified power demand with less computational time and it also suggests to the GENCOs operator which unit to be put into generation to avoid the complexity of the unit commitment problem.

In every stage of decision making, the decision- making alternative can be discrete or continuous. Further it can be classified into single criteria and multi-criteria types. Also these criteria can be quantitative, qualitative or be the combination of both [21].The AHP (Analytical Hierarchy Process) 
is one of the most comprehensive systems which are designed for multiple criteria decisions, because this type of design can provide the possibility of formulating the above quantitative and qualitative criteria issues [22]. Therefore the combination of IPPD and AHP is the paper contribution. This combination gives better profit than other methodologies such as IPPD with Muller method etc. [20].

In Day Ahead market, the GENCOs submit their bid for the next $24 \mathrm{~h}$. Based on supply bids and demand, Market clearing prices (MCP) are modeled and included electricity market to provide a high profit to GENCOs.

In this paper, PBUC problem is also defined and solved for a smart grid environment where RESs and EVs are integrated with thermal units provide low emission, low operating cost and high GENCO profit in a Day ahead market.

This proposed strategy has been tested on a standard system with ten thermal units including Renewable energy sources and Electric vehicles. Simulation results prove that the proposed method provides maximum profit to GENCOs when compared to other methodologies.

In assessment, compared to the previous related works, the main contribution of this study are:

- Market clearing price (MCP) is modeled and included in PBUC problem. In Day market, this MCP provides maximum social welfare for both GENCOs and Consumers.

- A novel combination of solution methodology: Improved Pre-prepared power demand (IPPD) table and Analytical Hierarchy method (AHP) for solving the optimal day ahead scheduling problem as an another contribution.

- The intelligent and flexible operation of EVs sources or loads is implemented and the effectiveness of EVs in a smart grid with RESs and the maximum utilization of RESs through the use of EVs to reduce cost and emission in a smart grid is illustrated.

This paper organized as follows. Sections 2 and 3 deals with PBUC problem formulation and Energy Market strategies respectively. Sections 4 and 5 apply proposed solution methodology for PBUC and conventional costs based unit commitment (CBUC) problems respectively and compare the results. Renewable energy sources (solar \& wind) and Electric vehicle system are introduced in Sect. 6. Simulation results of different cases are presented in Sect. 7. The conclusion \& future scope of research work is presented in Sect. 8 and future scope of research work is presented in Sect. 9.

\section{Problem Formulation}

The PBUC is used to determine the generating unit schedule for maximization of GENCOs profit. The expected value of the profit is computed from expected revenue minus incurred total operating cost for a given period [23]. The PBUC problem can be mathematically represented as

Max Profit $=$ Total Revenue cost - Total Operating Cost

Subject to the constraints explained in Sect. 2.1, 2.2, 2.3, $2.4,2.5,2.6$ and 2.7

\subsection{Power Demand Constraint}

The total power output of the thermal generators and other sources may be less than or equal to the load of the corresponding hour and it is represented in Fig. 1.

$\sum_{\mathrm{i}=1}^{\mathrm{n}} \mathrm{P}_{\mathrm{gen}}^{(\mathrm{i}, \mathrm{t})}+\mathrm{P}_{\mathrm{s}}^{(\mathrm{t})}+\mathrm{P}_{\mathrm{w}}^{(\mathrm{t})}+\mathrm{P}_{\mathrm{EV}}^{(\mathrm{t})} \leq \mathrm{PD}^{(\mathrm{t})} ; 1 \leq \mathrm{i} \leq \mathrm{n}$

\subsection{Generator Limits Constraint}

The output power of each thermal generator must be operated within a specified range.

$\mathrm{P}_{\text {gen }}^{\min (\mathrm{i}, \mathrm{t})} \leq \mathrm{P}_{\text {gen }}^{(\mathrm{i}, \mathrm{t})} \leq \mathrm{P}_{\text {gen }}^{\max (\mathrm{i}, \mathrm{t})} ; 1 \leq \mathrm{i} \leq \mathrm{n}$

\subsection{Reserve Constraint}

$\sum_{\mathrm{i}=1}^{\mathrm{n}}\left(\mathrm{P}_{\mathrm{res}}^{(\mathrm{i}, \mathrm{t})} \cdot \mathrm{S}^{(\mathrm{i}, \mathrm{t})}\right) \leq \mathrm{SR}^{(\mathrm{t})} ; 1 \leq \mathrm{i} \leq \mathrm{n}$

$0 \leq \mathrm{P}_{\text {res }}^{(\mathrm{i}, \mathrm{t})} \leq\left(\mathrm{P}_{\mathrm{gen}}^{\max (\mathrm{i}, \mathrm{t})}-\mathrm{P}_{\mathrm{gen}}^{\min (\mathrm{i}, \mathrm{t})}\right) ; 1 \leq \mathrm{i} \leq \mathrm{n}$

$\mathrm{P}_{\text {res }}^{(\mathrm{i}, \mathrm{t})}+\mathrm{P}_{\mathrm{gen}}^{(\mathrm{i}, \mathrm{t})} \leq \mathrm{P}_{\text {gen }}^{\max (\mathrm{i}, \mathrm{t})}$

\subsection{Minimum Up/down time}

$\mathrm{T}_{\mathrm{on}_{\mathrm{i}}} \geq \mathrm{M}_{\mathrm{up}_{\mathrm{i}}} ; \mathrm{i}=1 \ldots \mathrm{n}$

$\mathrm{T}_{\text {off }_{\mathrm{i}}} \geq \mathrm{M}_{\text {down }_{\mathrm{i}}} ; \mathrm{i}=1 \ldots \mathrm{n}$

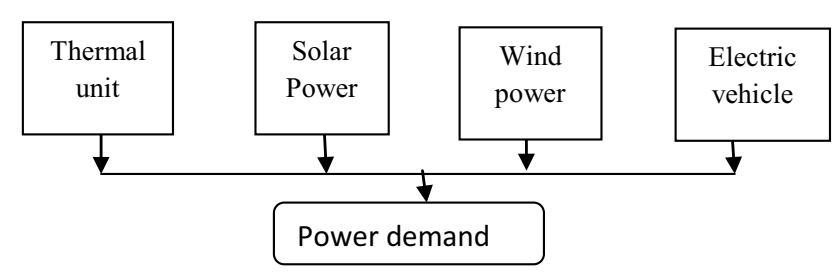

Fig. 1 Schematic diagram of integrated wind, solar and electric vehicle with thermal power units 


\subsection{Function of Output Power of Wind Energy System}

The function of output power of wind energy system with respect to wind speed is given by [24]

$\mathrm{P}_{\mathrm{w}}^{(\mathrm{t})}=0.15 \times \mathrm{A} \times \mathrm{R}^{2} \times v^{3} \times \rho \times \eta$

\subsection{Function of Output Power of Solar Energy System}

The function of output power of solar energy system with respect to solar radiation is given by $[25,26]$.

$\mathrm{P}_{\mathrm{s}}^{(\mathrm{t})}=0.5 \times \mathrm{G} \times \mathrm{A}_{\mathrm{PV}} \times \xi_{\mathrm{PV}}$

\subsection{Power Output Limit on Electric Vehicle System}

Electric vehicles will play two important roles when they are connected to smart grid. These EVs will appear as load during charging and they are also used as storage units to supply energy to the remaining load demands, if the batteries have the sufficient spare energy [27].

The battery of electric vehicle acts as a source of stored energy to provide a number of ancillary services to supply voltage control. The battery of electric vehicle is chemical storage devices and they are exponential functions over time [28].The power output function with respect to electric vehicle travelling power is given by

$\mathrm{P}_{\mathrm{EV}}^{(\mathrm{t})}=0.5 \times \xi \mathrm{N}_{\mathrm{Ev} 2 \mathrm{G}} \mathrm{P}_{\mathrm{V}}\left(\Psi_{\text {pre }}-\Psi_{\text {dep }}\right)$

\section{Energy Market Strategies}

\subsection{Market Structure}

In deregulated power market, the GENCOs can sell real power in an energy market and reserve power in a reserve market directly to the power pools by competing in the energy market. The changes in energy and reserve have a direct impact on the price of power and reserve bids [29]. In deregulated power system, different market operators participate in electricity market to sell and purchase power and reserve [30].
In Day Ahead market, the GENCOs submit their bid for the next $24 \mathrm{~h}$. Based on supply bids and demand, a market operator determines Market clearing prices (MCP) which plays an important role in electricity market with an objective of maximizing social welfare function where both GENCOs and consumers are benefited and power quantities are awarded [31]. In this process, the system operator clears the generation bids based on the price ordered from lower to higher prices. If the GENCOs bids higher than the Market Clearing Price (MCP), then such bid will be eliminated for little duration [32].

\subsection{Optimal Bidding Strategy for PBUC}

Optimal bidding parameters for both power and reserve are selected for each generating unit to maximize its profit. In bidding process, the fuel cost, startup cost, unit generating limits and minimum up and down time constraints are taken into account to ensure that the generating unit is capable of meeting the power demand [33, 34]. From the Eq. (1), the Total Revenue Cost (TRC) consists of Energy market revenue (EMR) and Reserve market revenue (RMR) and Total Operating Cost (TOC) denotes the production cost of thermal units. Therefore the profit obtained by GENCOs in deregulated market is represented as

Max profit

$=($ Energy Market Revenue + Reserve Market Revenue $)$

- Total Operating Cost

$\mathrm{P}_{\mathrm{T}}^{(\mathrm{i}, \mathrm{t})}=\sum_{\mathrm{t}=1}^{\mathrm{T}}\left(\mathrm{P}_{\mathrm{gen}}^{(\mathrm{i}, \mathrm{t})}+\mathrm{P}_{\mathrm{s}}^{\mathrm{t}}+\mathrm{P}_{\mathrm{w}}^{\mathrm{t}}+\mathrm{P}_{\mathrm{EV}}^{\mathrm{t}}\right) \mathrm{MCP}^{(\mathrm{t})}$

Can be rewritten as

Energy Market Revenue $=\sum_{\mathrm{t}=1}^{\mathrm{T}}\left(\mathrm{P}_{\mathrm{T}}^{(\mathrm{i}, \mathrm{t})}\right) \mathrm{MCP}^{(\mathrm{t})}$

Where, $\mathrm{P}_{\mathrm{T}}^{(\mathrm{i}, \mathrm{t})}=\mathrm{P}_{\text {gen }}^{(\mathrm{i}, \mathrm{t})}+\mathrm{P}_{\mathrm{s}}^{\mathrm{t}}+\mathrm{P}_{\mathrm{w}}^{\mathrm{t}}+\mathrm{P}_{\mathrm{EV}}^{\mathrm{t}}$

Reserve Market Revenue $=\sum_{\mathrm{t}=1}^{\mathrm{T}}\left(\mathrm{P}_{\text {res }}^{(\mathrm{i}, \mathrm{t})}\right) \mathrm{MCR}^{(\mathrm{t})}$

$\operatorname{MCP}^{(t)}=\max \left(c_{i}+b_{i} P_{\text {gen }}^{(i, t)}\right) / P_{\text {gen }}^{(i, t)}$

$\mathrm{MCP}^{(\mathrm{t})}=\max \left(\mathrm{c}_{\mathrm{i}}+\mathrm{b}_{\mathrm{i}} \mathrm{P}_{\text {res }}^{(\mathrm{i}, \mathrm{t})}\right) / \mathrm{P}_{\text {res }}^{(\mathrm{i}, \mathrm{t})}$

$\mathrm{TOC}=\sum_{\mathrm{t}=1}^{\mathrm{T}} \sum_{\mathrm{t}=1}^{\mathrm{T}}\left\{(1-r) \cdot \mathrm{F}\left(\mathrm{P}_{\text {gen }}^{(\mathrm{i}, \mathrm{t})}\right)+r \cdot\left[\mathrm{F}\left(\mathrm{P}_{\text {gen }}^{(\mathrm{i}, \mathrm{t})}\right)+\mathrm{F}\left(\mathrm{P}_{\text {res }}^{(\mathrm{i}, \mathrm{t})}\right)\right]\right\} \mathrm{S}^{(\mathrm{i}, \mathrm{t})}+\mathrm{SU}^{(\mathrm{i}, \mathrm{t})}$ 
where, $F\left(P_{\text {gen }}^{(\mathrm{i}, t)}\right)=\mathrm{a}_{\mathrm{i}}+\mathrm{b}_{\mathrm{i}} \mathrm{P}_{\text {gen }}^{(\mathrm{i}, \mathrm{t})}+\mathrm{c}_{\mathrm{i}} \mathrm{P}_{\text {gen }}^{(\mathrm{i}, \mathrm{t})_{2}}$ and

$\mathrm{F}\left(\mathrm{P}_{\text {res }}^{(\mathrm{i}, \mathrm{t})}\right)=\mathrm{a}_{\mathrm{i}}+\mathrm{b}_{\mathrm{i}} \mathrm{P}_{\text {res }}^{(\mathrm{i}, \mathrm{t})}+\mathrm{c}_{\mathrm{i}} \mathrm{P}_{\text {res }}^{(\mathrm{i}, \mathrm{t})_{2}}$

In this paper, emission curve is also considered and represented as

$\operatorname{EC}\left(\mathrm{P}_{\text {gen }}^{(\mathrm{i}, \mathrm{t})}\right)=\alpha_{\mathrm{i}}+\beta_{\mathrm{i}} \mathrm{P}_{\text {gen }}^{(\mathrm{i}, \mathrm{t})}+\gamma_{\mathrm{i}} \mathrm{P}_{\text {gen }}^{(\mathrm{i}, \mathrm{t})_{2}}$

where $\alpha_{i}, \beta_{\mathrm{i}}$ and $\gamma_{\mathrm{i}}$ are emission coefficients of thermal units.

\section{Solution Methodology for Profit Based Unit Commitment (PBUC)}

The solutions for the PBUC problem are obtained in the following stages [35].

Stage 1: Commitment of units using IPPD and RIPPD tables.

Stage 2: Analytical Hierarchy Process based optimal scheduling.

\subsection{Formation of the IPPD Table}

The procedure of IPPD table formation is given below.

Step1: Determination of $\lambda_{i}^{\text {min }}$ and $\lambda_{i}^{\text {max }}$ for all generating unit at their $\mathrm{P}_{\text {gen }}^{\min (\mathrm{i}, \mathrm{t})}$ and $\mathrm{P}_{\text {gen }}^{\max (\mathrm{i}, \mathrm{t})}$. Arrange these $\lambda$ values in ascending order and indicate them as

$\lambda_{\mathrm{j}}$ where $\mathrm{j}=1,2, .2 \mathrm{n}$

Step2: Determine output power $\mathrm{P} P_{\text {gen }}^{(i, t)}=(\lambda \mathrm{j}-\mathrm{bi}) / 2$ ci for all generators at each $\lambda_{\mathrm{j}}$ value. The generator constraints such as minimum and maximum output power are considered as follows

(a) If $\lambda_{\mathrm{i}} \leq \lambda_{\mathrm{j}}^{\min }$ then $\mathrm{P}_{\text {gen }}^{(\mathrm{i}, \mathrm{t})}=0$

(b) If $\lambda_{\mathrm{j}}=\lambda_{\mathrm{i}}^{\min }$ then $\mathrm{P}_{\mathrm{gen}}^{(\mathrm{i}, \mathrm{t})}=\mathrm{P}_{\mathrm{gen}}^{\min (\mathrm{i}, \mathrm{t})}$

(c) If $\lambda_{\mathrm{j}} \geq \lambda_{\mathrm{i}}^{\max }$ then $\mathrm{P}_{\mathrm{gen}}^{(\mathrm{i}, \mathrm{t})}=\mathrm{P}_{\mathrm{gen}}^{\max (\mathrm{i}, \mathrm{t})}$

Step3: The sum of output power (SOP) for each $\lambda_{j}$ value is determined.

The results of steps 1-3 are arranged in a table known as Improved Pre-Prepared Power Demand (IPPD) table [26].

This IPPD table provides an effective data structure for the formation of RIPPD table which will reveal the units to be committed. Later optimal scheduling of units is to be performed based on RIPPD Table. The proposed method which is being discussed has been tested on a standard power system of ten thermal units. The input characteristics of the test system are given in Table 1.

The steps 1-3 are applied on the test system. The lambda values at $\mathrm{P}_{\text {gen }}^{\min (i, t)}$ and $\mathrm{P}_{\text {gen }}^{\max (\mathrm{i}, \mathrm{t})}$ are determined and listed in Table 2 and then for these maximum and minimum lambda values, the sum of output power (SOP) is determined and arranged in Table 3 known as IPPD table.

\subsection{Formation of the Reduced Improved Pre-prepared power demand (RIPPD) table}

In generation companies (GENCOs), Maximum profit can be obtained only when the market clearing price (MCP) is
Table 1 Input characteristic of ten thermal generating units (GUs) system
Table 2 Lambda values at $\mathrm{P}_{\text {gen }}^{\min }$ and $\mathrm{P}_{\text {gen }}^{\max }$ in $\$ / \mathrm{MW}$

\begin{tabular}{lllllllllll}
\hline (GUs) & GU1 & GU2 & GU3 & GU4 & GU5 & GU6 & GU7 & GU8 & GU9 & GU10 \\
\hline $\mathrm{P}_{\text {gen }}^{\max }(\mathrm{MW})$ & 455 & 455 & 130 & 130 & 162 & 80 & 85 & 55 & 55 & 55 \\
$\mathrm{P}_{\text {gen }}^{\min }(\mathrm{MW})$ & 150 & 150 & 20 & 20 & 25 & 20 & 25 & 10 & 10 & 10 \\
$\mathrm{a}(\$ / \mathrm{h})$ & 1000 & 970 & 700 & 680 & 450 & 370 & 480 & 660 & 665 & 670 \\
$\mathrm{~b}(\$ / \mathrm{MWh})$ & 16.2 & 17.3 & 16.6 & 16.5 & 19.7 & 22.3 & 27.7 & 25.9 & 27.3 & 27.8 \\
$\mathrm{c}\left(\$ / \mathrm{MW}^{2} \mathrm{~h}\right)$ & 0.0048 & 0.0003 & 0.0020 & 0.0021 & 0.0038 & 0.0071 & 0.0007 & 0.0041 & 0.0022 & 0.0017 \\
$\mathrm{MUi}(\mathrm{h})$ & 8 & 8 & 5 & 5 & 6 & 3 & 3 & 1 & 1 & 1 \\
$\mathrm{MDi}(\mathrm{h})$ & 8 & 8 & 5 & 5 & 6 & 3 & 3 & 1 & 1 & 1 \\
$\mathrm{Scost}(\$)$ & 4500 & 5000 & 550 & 560 & 900 & 170 & 260 & 30 & 30 & 30 \\
$\alpha_{\mathrm{i}}($ ton $/ \mathrm{h})$ & 10.34 & 10.34 & 30.04 & 30.04 & 32.00 & 32.00 & 33.00 & 33.00 & 35.00 & 36.00 \\
$\beta_{\mathrm{i}}($ ton $/ \mathrm{h})$ & -2.44 & -2.44 & -0.41 & -0.41 & -0.38 & -0.38 & -0.39 & -0.39 & -0.40 & -0.40 \\
$\gamma_{\mathrm{i}}($ ton $/ \mathrm{h})$ & 0.0031 & 0.0031 & 0.0051 & 0.0051 & 0.0034 & 0.0034 & 0.0047 & 0.0047 & 0.0047 & 0.0047 \\
\hline
\end{tabular}

\begin{tabular}{lcccccccccc}
\hline & GU1 & GU2 & GU3 & GU4 & GU5 & GU6 & GU7 & GU8 & GU9 & GU10 \\
\hline $\mathrm{P}_{\text {gen }}^{\min }(\mathrm{MW})$ & 16.33 & 17.35 & 16.68 & 16.58 & 19.90 & 20.54 & 27.78 & 26.00 & 27.31 & 27.82 \\
$\mathrm{P}_{\text {gen }}^{\max }(\mathrm{MW})$ & 16.63 & 17.54 & 17.12 & 17.05 & 20.98 & 23.39 & 27.87 & 26.37 & 27.51 & 27.98 \\
\hline
\end{tabular}


Table 3 IPPD table for 10 generating units system in MW

\begin{tabular}{llrrrrrrrrrrrr}
\hline s1 & $\lambda(\$ / M W)$ & P1 & P2 & P3 & P4 & P5 & P6 & P7 & P8 & P9 & P10 & $\begin{array}{l}\text { Sum of } \\
\text { power } \\
\text { (SOP) }\end{array}$ \\
\hline 1 & 16.33 & 150 & 0 & 0 & 0 & 0 & 0 & 0 & 0 & 0 & 0 & 150 \\
2 & 16.58 & 150 & 0 & 0 & 20 & 0 & 0 & 0 & 0 & 0 & 0 & 170 \\
3 & 16.63 & 455 & 0 & 0 & 20 & 0 & 0 & 0 & 0 & 0 & 0 & 475 \\
4 & 16.68 & 455 & 0 & 20 & 20 & 0 & 0 & 0 & 0 & 0 & 0 & 495 \\
5 & 17.05 & 455 & 0 & 20 & 130 & 0 & 0 & 0 & 0 & 0 & 0 & 605 \\
6 & 17.12 & 455 & 0 & 130 & 130 & 0 & 0 & 0 & 0 & 0 & 0 & 715 \\
7 & 17.35 & 455 & 150 & 130 & 130 & 0 & 0 & 0 & 0 & 0 & 0 & 865 \\
8 & 17.54 & 455 & 455 & 130 & 130 & 0 & 0 & 0 & 0 & 0 & 0 & 1170 \\
9 & 19.90 & 455 & 455 & 130 & 130 & 25 & 0 & 0 & 0 & 0 & 0 & 1195 \\
10 & 20.99 & 455 & 455 & 130 & 130 & 162 & 0 & 0 & 0 & 0 & 0 & 1332 \\
11 & 22.54 & 455 & 455 & 130 & 130 & 162 & 20 & 0 & 0 & 0 & 0 & 1352 \\
12 & 23.48 & 455 & 455 & 130 & 130 & 162 & 80 & 0 & 0 & 0 & 0 & 1412 \\
13 & 26.00 & 455 & 455 & 130 & 130 & 162 & 80 & 0 & 10 & 0 & 0 & 1422 \\
14 & 26.37 & 455 & 455 & 130 & 130 & 162 & 80 & 0 & 55 & 0 & 0 & 1466 \\
15 & 27.31 & 455 & 455 & 130 & 130 & 162 & 80 & 0 & 55 & 10 & 0 & 1477 \\
16 & 27.51 & 455 & 455 & 130 & 130 & 162 & 80 & 0 & 55 & 55 & 0 & 1522 \\
17 & 27.78 & 455 & 455 & 130 & 130 & 162 & 80 & 25 & 55 & 55 & 0 & 1547 \\
18 & 27.82 & 455 & 455 & 130 & 130 & 162 & 80 & 85 & 55 & 55 & 0 & 1607 \\
19 & 27.87 & 455 & 455 & 130 & 130 & 162 & 80 & 85 & 55 & 55 & 10 & 1617 \\
20 & 27.98 & 455 & 455 & 130 & 130 & 162 & 80 & 85 & 55 & 55 & 55 & 1662 \\
\hline & & & & & & & & & & & &
\end{tabular}

higher than the increment fuel cost $(\lambda)$ of the generating unit at that hours. Therefore, the market clearing price is an important factor to select the Reduced IPPD from the IPPD table. There are two ways to construct RIPPD from IPPD table [36]. They are

(i) At the predicted forecasted price, two rows from the Improved Pre-prepared power demand table are selected in such a way that the price should lie within the lambda limits. Assume $m$ and $m+1$ are the corresponding rows.

(ii) At the predicted forecasted demandPD ${ }^{(t)}$, two rows from Improved Pre-prepared power demand are selected in such a way that the predicted power should lie within the lambda limits. Assume $\mathrm{n}$ and $\mathrm{n}+1$ are the corresponding rows. If $m<n$, then RIPPD table is selected based on option 1, otherwise option 2 is selected. Once RIPPD table is obtained, the Reduced Committed Units (RCU) table could be formed by simply assigning +1 if the output unit is ON and 0 if the unit is OFF. The RCU table will have binary elements indicating the status of all committed units.

The predicted load demand and reserve is presented in Table 4 and For the test system, Market Clearing Price (MCP) for power and reserve for test system is given in Table 5. The RIPPD table for different power demands are constructed and given in the Table 6 . In this Table 6, the first row provides the initial information of committed units. If MCP is greater than the lambda at maximum output power, then that corresponding unit will be turned ON.

Therefore the second row of the above RIPPD table gives the final information of units to be committed and also the transition of unit commitment from one lambda to another lambda in the table. The RCU table is obtained from the

Table 4 Forecasted power demand (PD) and Spinning reserve (SR) for test system in MW

\begin{tabular}{|c|c|c|c|c|c|c|c|c|c|c|c|c|}
\hline $\mathrm{Hr}$ & 1 & 2 & 3 & 4 & 5 & 6 & 7 & 8 & 9 & 10 & 11 & 12 \\
\hline PD & 700 & 750 & 850 & 950 & 1000 & 1100 & 1150 & 1200 & 1300 & 1400 & 1450 & 1500 \\
\hline SR & 70 & 75 & 85 & 95 & 100 & 110 & 115 & 120 & 130 & 140 & 145 & 150 \\
\hline $\mathrm{Hr}$ & 13 & 14 & 15 & 16 & 17 & 18 & 19 & 20 & 21 & 22 & 23 & 24 \\
\hline PD & 1400 & 1300 & 1200 & 1050 & 1000 & 1100 & 1200 & 1400 & 1300 & 1100 & 900 & 800 \\
\hline SR & 140 & 130 & 120 & 105 & 100 & 110 & 120 & 140 & 130 & 110 & 90 & 80 \\
\hline
\end{tabular}


RIPPD table by substituting binary values in such a way that if the output power is non zero then it will be replaced as 1. For forecasted power demand of $1500 \mathrm{MW}$, the status of generating units is given in Table 7 as an example.

The procedures of de-commitment of units and Minimum up and down time constraints are also included in the PBUC problem.

\subsection{Analytic Hierarchy Process (AHP) Method}

The Analytic Hierarchy Process (AHP) is a theory of measurement through pair wise comparisons and relies on the judgments of experts to derive priority scales. The comparisons are made using a scale of absolute judgments that shows how much one element dominates on another element with respect to other factors represents how much more; one element dominates another with respect to a given attribute. The judgments may be inconsistent, and how to measure inconsistency and improve the judgments, when possible to obtain better consistency is a concern of the AHP [37].

The AHP is a decision-making approach. It offers alternatives and criteria, evaluates trade-off and applies a synthesis to reach a final decision. The PBUC problem can be solved with this approach by making decision effectively by ranking units in term of their values.

The pictorial representation of proposed methodology is given in the Fig. 2.

Here the decision in Generation Company is taken based on priorities and to decompose the decision the following steps are followed.

Table 5 Market clearing price for power and reserve

\begin{tabular}{llllllllllllll}
\hline Hour & 1 & 2 & 3 & 4 & 5 & 6 & 7 & 8 & 9 & 10 & 11 \\
\hline MCP (\$) & 21.63 & 20.59 & 19.72 & 21.73 & 21.73 & 21.73 & 21.73 & 21.73 & 21.73 & 21.73 & 21.73 & 21.73 \\
MCR (\$) & 32.45 & 30.88 & 29.58 & 32.59 & 32.59 & 32.59 & 32.59 & 32.59 & 32.59 & 32.59 & 32.59 & 32.59 \\
\hline Hour & 13 & 14 & 15 & 16 & 17 & 18 & 19 & 20 & 21 & 22 & 23 & 24 \\
\hline MCP (\$) & 23.72 & 23.72 & 23.72 & 23.72 & 20.26 & 21.98 & 21.98 & 21.98 & 21.98 & 21.98 & 20.35 & 21.38 \\
MCR (\$) & 35.58 & 35.58 & 35.58 & 35.58 & 30.40 & 32.97 & 32.97 & 32.97 & 32.97 & 32.97 & 30.52 & 32.08 \\
\hline
\end{tabular}

Table 6 RIPPD table for various power demands

Table 7 Status of generating units for the power demand of $1500 \mathrm{MW}$

\begin{tabular}{|c|c|c|c|c|c|c|c|c|c|c|c|c|}
\hline \multirow[t]{2}{*}{ Power demand (MW) } & \multirow{2}{*}{$\begin{array}{l}\text { Lambda } \\
\text { \$/MW }\end{array}$} & \multicolumn{10}{|c|}{ Output power (MW) } & \multirow{2}{*}{$\begin{array}{l}\text { SOP } \\
(\mathrm{MW})\end{array}$} \\
\hline & & $\mathrm{P} 1$ & $\mathrm{P} 2$ & P3 & $\mathrm{P} 4$ & P5 & P6 & P7 & P8 & P9 & $\mathrm{P} 10$ & \\
\hline \multirow[t]{2}{*}{700} & 17.05 & 455 & 0 & 20 & 130 & 0 & 0 & 0 & 0 & 0 & 0 & 605 \\
\hline & 17.12 & 455 & 0 & 130 & 130 & 0 & 0 & 0 & 0 & 0 & 0 & 715 \\
\hline \multirow[t]{2}{*}{$750-850$} & 17.12 & 455 & 0 & 130 & 130 & 0 & 0 & 0 & 0 & 0 & 0 & 715 \\
\hline & 17.35 & 455 & 150 & 130 & 130 & 0 & 0 & 0 & 0 & 0 & 0 & 865 \\
\hline \multirow[t]{2}{*}{$950-1150$} & 17.35 & 455 & 150 & 130 & 130 & 0 & 0 & 0 & 0 & 0 & 0 & 865 \\
\hline & 17.54 & 455 & 455 & 130 & 130 & 0 & 0 & 0 & 0 & 0 & 0 & 1170 \\
\hline \multirow[t]{2}{*}{ 1200-1300 } & 19.90 & 455 & 455 & 130 & 130 & 25 & 0 & 0 & 0 & 0 & 0 & 1195 \\
\hline & 20.99 & 455 & 455 & 130 & 130 & 162 & 0 & 0 & 0 & 0 & 0 & 1332 \\
\hline \multirow[t]{2}{*}{1400} & 22.54 & 455 & 455 & 130 & 130 & 162 & 20 & 0 & 0 & 0 & 0 & 1352 \\
\hline & 23.48 & 455 & 455 & 130 & 130 & 162 & 80 & 0 & 0 & 0 & 0 & 1412 \\
\hline \multirow[t]{2}{*}{1450} & 26.00 & 455 & 455 & 130 & 130 & 162 & 80 & 0 & 10 & 0 & 0 & 1422 \\
\hline & 26.37 & 455 & 455 & 130 & 130 & 162 & 80 & 0 & 55 & 0 & 0 & 1466 \\
\hline \multirow[t]{2}{*}{1500} & 27.31 & 455 & 455 & 130 & 130 & 162 & 80 & 0 & 55 & 10 & 0 & 1477 \\
\hline & 27.51 & 455 & 455 & 130 & 130 & 162 & 80 & 0 & 55 & 55 & 0 & 1522 \\
\hline
\end{tabular}

\begin{tabular}{|c|c|c|c|c|c|c|c|c|c|c|c|}
\hline \multirow{2}{*}{$\begin{array}{l}\lambda \\
\$ / \mathrm{MW}\end{array}$} & \multicolumn{10}{|c|}{ Output power (MW) } & \multirow{2}{*}{$\begin{array}{l}\text { SOP } \\
\text { MW }\end{array}$} \\
\hline & $\mathrm{P} 1$ & $\mathrm{P} 2$ & P3 & $\mathrm{P} 4$ & P5 & P6 & $\mathrm{P} 7$ & P8 & P9 & P10 & \\
\hline 27.31 & 1 & 1 & 1 & 1 & 1 & 1 & 0 & 1 & 1 & 0 & 1477 \\
\hline 27.51 & 1 & 1 & 1 & 1 & 1 & 1 & 0 & 1 & 1 & 0 & 1522 \\
\hline
\end{tabular}




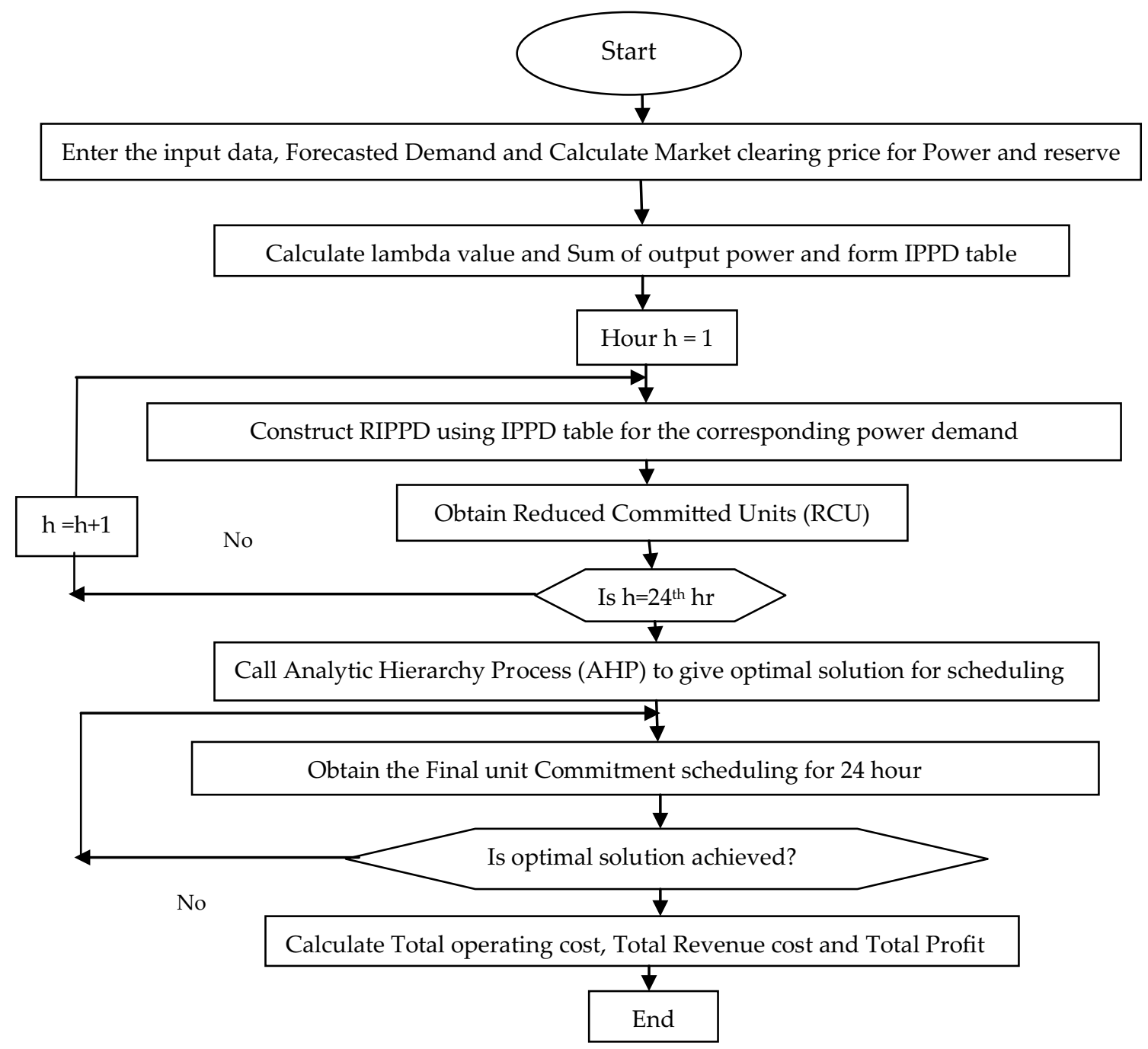

Fig. 2 Flowchart of proposed method

1. Define the type of problem and determine the different kind of knowledge sought.

2. Generally the decision hierarchy is generated by the top management and then the objectives of an optimization are formulated from a broad perspective, through the intermediate levels (criteria on which subsequent elements depend) to the lowest level (which usually is a set of the alternatives).

3. Construct a set of pair wise comparison matrices. Each element of the upper level is used to compare with other elements in the level immediately below with respect to it.

4. Use the priorities obtained from the comparisons to weigh the priorities in the level immediately below. Do this for every element. Then for each element in the level below add its weighed values and obtain its overall or global priority.

In this paper, AHP method dispatches the demand in PBUC problem to maximize GENCOs profit. The performance of AHP is well tested for many optimization techniques in many literatures. The AHP method provides high applicability and efficiency to solve PBUC problem in Day a head market and achieve the highest profit.

\section{Comparison of PBUC with CBUC}

Generation scheduling problems can be solved by either Cost Based Unit Commitment or Profit Based Unit commitment objective functions [38]. Generally, CBUC problem is considered as a cooperative case whereas PBUC problem as competitive case. The objective of CBUC is to minimize the total operating cost by optimal scheduling of generating units by considering all the constraints. Whereas the objective of PBUC scheduling is to maximize the profit of GENCOs due to constraints and market price variations.

In cooperative case, the GENCOs should meet demand with minimum reserve requirements. So, the hourly load 
should be less than the total generation capacity and the system should work in a self sufficient mode [38].

In the competitive case, the system generation can be equal or lower than demand required. Usually, the profits of GENCOs are more in Competitive markets since GENCOs offer bids in such a way that it will attain a maximum profit [38]. The proposed methodology provides a better profit individually for PBUC and CBUC problems when compared with other methods(as published in many literature) such as Memory management algorithm (MMA), Muller, Improved Particle swarm optimization (PSO), Tabu search -RP and Tabu search-TRP etc. This is shown in Fig. 3 for PBUC and Table 8 for CBUC problems.

The overall profit of CBUC and PBUC problems defined for a standard 10 unit system (introduced in Sect. 4) are compared in Table 9. It is shown that PBUC provides a maximum profit of $\$ 137595.25$ whereas CBUC presents $\$ 75093$ in Day ahead scheduling.

\section{Introduction of Renewable Energy Sources and Electric Vehicle System}

In this research work, a modified test system consists of Thermal units, Renewable Energy Sources (RESs) and Electric Vehicles (EVs) is constructed and the effect of solar, wind and Electric vehicle power output is considered on scheduling of ten units generating system. A multiple scale factor is used to model the wind and solar farms. By using this scale the power production level of solar and wind is found. The power output of each solar and wind is proportional to resource potential in term of solar irradiation and wind speed respectively [39]. In this paper, the actual solar irradiation and wind velocity is obtained from Kuala Terengganu, Malaysia [40] in given the Table 10. In Malaysia, the solar irradiation is relatively high compared to other countries. From the solar irradiation, the output power of the solar energy generated from PV panel can be calculated using Eq. (10). Area of the PV module is $1.6 \mathrm{~m}^{2}$ and PV module efficiency is $16 \%$ [41].
Table 8 CBUC-operating cost comparison of proposed method with different methods

\begin{tabular}{ll}
\hline Methods & Operating cost (\$) \\
\hline Dynamic programming [15] & 565,825 \\
Genetic algorithm [15] & 570,032 \\
Advanced PSO [19] & 563,942 \\
Proposed method & 554,637 \\
\hline
\end{tabular}

From the wind velocity [42], the output power of wind energy generated from wind turbine can be calculated using the Eq. (9). Radius of the wind turbine rotor $=80 \mathrm{~m}$, Air density $=1.2 \mathrm{~kg} / \mathrm{m}^{3}$, Efficiency factor $=40 \%$. Here solar energy is available from 7 am to $6 \mathrm{pm}$ and wind energy is available most of the time.. The Power generation from Renewable energy source for $24 \mathrm{~h}$ is graphically represented in Fig. 4 where total $\mathrm{P}_{\mathrm{s}}^{(\mathrm{t})}$ is $2709.54 \mathrm{MW}$ and $\mathrm{P}_{\mathrm{W}}^{(\mathrm{t})}$ is $2697.87 \mathrm{MW}$.

In the recent years, The Electric Vehicles has drawn the interest of researchers by providing the batteries power of Electric Vehicles to the micro-grid when parked or take power from the micro-grid to charge the batteries on the vehicle, known as vehicle to grid concept. It can be used as loads (or) sources in the application of smart grid. The vehicle to grid improves the load profile and further reduces system running cost and emission [43]. For practical application, the number of Electric Vehicles (EVs) in an electric power network can be estimated analytically based on the number of electricity clients or customers in that network. The Electric Vehicle parameter considered in this paper are as follows: Average vehicle battery capacity $\left(\mathrm{P}_{\mathrm{V}}\right)=15 \mathrm{kWh}$, Estimated number of Electric Vehicles in a small city $=50,000$. The output power of the Electric Vehicles can be calculated using Eq. (11). Departure Sum of charge $\left(\psi_{\text {dep }}\right)=50 \%$, Minimum number of electric vehicle $\left(\mathrm{N}_{V 2 G}\right)=50,000$ and system efficiency $(\xi)=85 \%$.

The maximum number of discharging vehicles at each hour, $10 \%$ of total vehicles.. Due to stochastic nature of solar and wind, the output power from solar and wind farms cannot be predicted accurately and uncertainty in Electric
Fig. 3 PBUC-profit comparison of proposed method with different methods

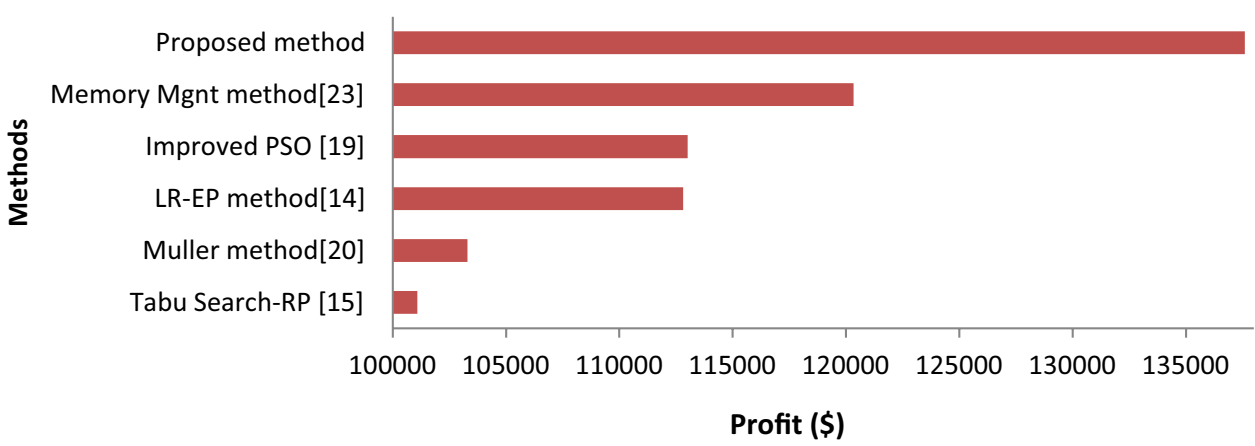


Table 9 Comparison of PBUC with CBUC

\begin{tabular}{|c|c|c|c|c|c|c|c|}
\hline \multirow[t]{2}{*}{$\mathrm{Hr}(\mathrm{h})$} & \multirow[t]{2}{*}{$\mathrm{Pd}(\mathrm{MW})$} & \multicolumn{3}{|c|}{ Cost based unit commitment (CBUC) } & \multicolumn{3}{|c|}{ Profit based unit commitment (PBUC) } \\
\hline & & $\begin{array}{l}\text { Total revenue } \\
\text { cost }(\$)\end{array}$ & $\begin{array}{l}\text { Total operating } \\
\text { cost }(\$)\end{array}$ & Profit $(\$)$ & Total revenue cost $(\$)$ & $\begin{array}{l}\text { Total operating } \\
\text { cost }(\$)\end{array}$ & Profit $(\$)$ \\
\hline 1 & 700 & 1550 & 13,683 & 1822 & $17,032.40$ & $13,413.13$ & 3619.27 \\
\hline 2 & 750 & 16,500 & 14,554 & 1946 & $17,676.75$ & $14,554.49$ & 3122.26 \\
\hline 3 & 850 & 19,635 & 16,302 & 3333 & $18,758.70$ & $16,301.88$ & 2456.82 \\
\hline 4 & 950 & 20,612 & 18,625 & 1647 & $17,644.90$ & $17,083.30$ & 561.61 \\
\hline 5 & 1000 & 21,158 & 20,469 & 629 & $26,568.40$ & $20,508.49$ & 6056.90 \\
\hline 6 & 1100 & 25,245 & 22,348 & 697 & $24,098.56$ & $20,738.13$ & 3363.43 \\
\hline 7 & 1150 & 25,875 & 22,755 & 3120 & $30,529.14$ & $23,274.96$ & 7254.18 \\
\hline 8 & 1200 & 25,916 & 24,150 & -34 & $27,012.00$ & $23,647.84$ & 3364.162 \\
\hline 9 & 1300 & 29,640 & 26,184 & 3456 & $323,093.04$ & $25,396.19$ & 6696.84 \\
\hline 10 & 1400 & 41,090 & 28,768 & 11,982 & $39,543.12$ & $28,574.19$ & $10,968.93$ \\
\hline 11 & 1450 & 42,572 & 30,699 & 11,813 & $37,954.56$ & $28,683.95$ & 9270.60 \\
\hline 12 & 1500 & 46,431 & 32,713 & 13,658 & $49,980.42$ & $31,787.56$ & $18,192.85$ \\
\hline 13 & 1400 & 34,440 & 28,768 & 5672 & $39,543.12$ & $28,403.59$ & $11,139.53$ \\
\hline 14 & 1300 & 31,850 & 26,184 & 5666 & $32,093.04$ & $24,846.19$ & 7246.84 \\
\hline 15 & 1200 & 24,150 & 26,325 & 2175 & $27,012.00$ & $23,647.84$ & 3364.162 \\
\hline 16 & 1050 & 21,005 & 23,415 & 2410 & $24,938.91$ & $20,369.29$ & 4569.60 \\
\hline 17 & 1000 & 16,799 & 20,133 & -3334 & $26,568.40$ & $19,338.52$ & 7229.87 \\
\hline 18 & 1100 & 24,255 & 21,879 & 2376 & $24,098.56$ & $20,735.13$ & 3363.43 \\
\hline 19 & 1200 & 25,974 & 23,106 & 2868 & $27,012.00$ & $23,647.84$ & 3364.162 \\
\hline 20 & 1400 & 26,501 & 31,356 & -5375 & $29,943.36$ & $26,487.58$ & 3455.77 \\
\hline 21 & 1300 & 27,027 & 27,268 & -241 & $39,543.12$ & $28,403.59$ & $11,139.53$ \\
\hline 22 & 1100 & 25,245 & 22,348 & 2897 & $24,098.56$ & $20,738.13$ & 3363.43 \\
\hline 23 & 900 & 20,475 & 17,178 & 3297 & $18,629.60$ & $17,177.90$ & 1451.09 \\
\hline 24 & 800 & 18,040 & 15,427 & 2613 & $18,406.8$ & $15,427.41$ & 2979.38 \\
\hline Total profit (\$) & & 625,940 & 554,637 & 75,093 & $961,779.5$ & $533,187.1$ & $137,595.25$ \\
\hline
\end{tabular}

Table 10 Actual solar irradiation and wind speed data

\begin{tabular}{|c|c|c|c|c|c|c|}
\hline Hour & 1 & 2 & 3 & 4 & 5 & 6 \\
\hline $\mathrm{G}\left(\mathrm{W} / \mathrm{m}^{2}\right)$ & 0 & 0 & 0 & 0 & 0 & 0 \\
\hline$v(\mathrm{~m} / \mathrm{s})$ & 16.94 & 8.8 & 5.0 & 8.8 & 11.89 & 5.0 \\
\hline Hour & 7 & 8 & 9 & 10 & 11 & 12 \\
\hline $\mathrm{G}\left(\mathrm{W} / \mathrm{m}^{2}\right)$ & 90 & 414 & 756 & 1816 & 1205 & 1006 \\
\hline$v(\mathrm{~m} / \mathrm{s})$ & 5.0 & 25.3 & 31.9 & 29.1 & 31.1 & 36.87 \\
\hline Hour & 13 & 14 & 15 & 16 & 17 & 18 \\
\hline $\mathrm{G}\left(\mathrm{W} / \mathrm{m}^{2}\right)$ & 4262 & 4982 & 3450 & 2428 & 718 & 36 \\
\hline$v(\mathrm{~m} / \mathrm{s})$ & 36.98 & 35.4 & 36.2 & 36.9 & 33.26 & 23.03 \\
\hline Hour & 19 & 20 & 21 & 22 & 23 & 24 \\
\hline $\mathrm{G}\left(\mathrm{W} / \mathrm{m}^{2}\right)$ & 0 & 0 & 0 & 0 & 0 & 0 \\
\hline$v(\mathrm{~m} / \mathrm{s})$ & 28.19 & 26.0 & 22.3 & 33.4 & 32.54 & 32.54 \\
\hline
\end{tabular}


Fig. 4 Power generation of renewable energy for $24 \mathrm{~h}$ a Solar energy source and $\mathbf{b}$ Wind energy source
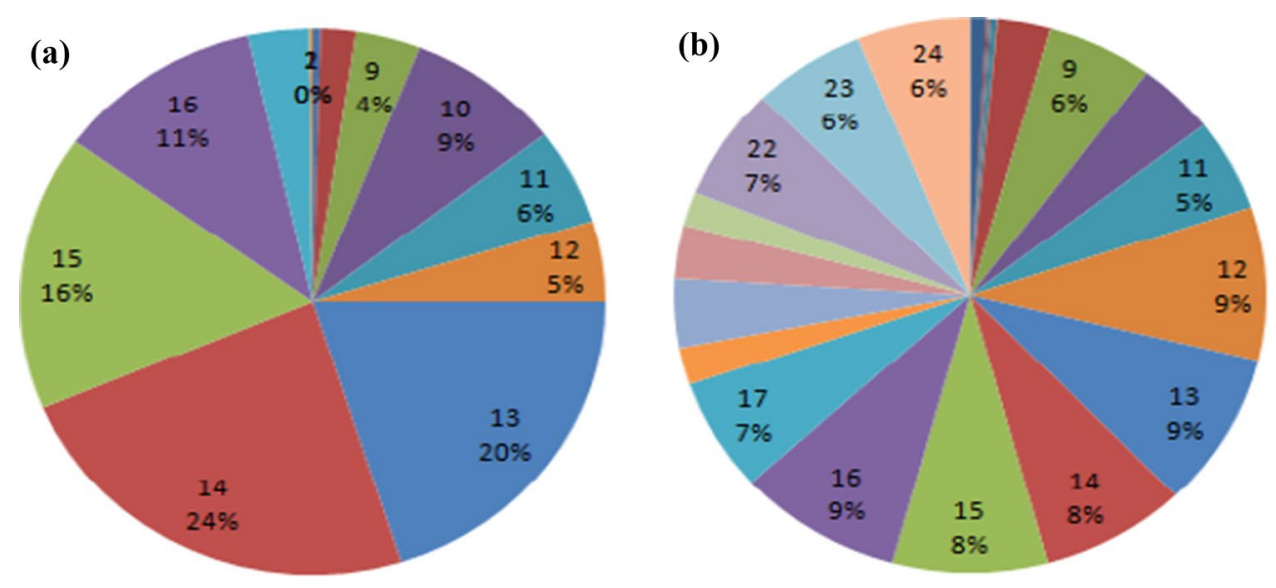

Table 11 An optimal distribution of electric vehicles in $24 \mathrm{~h}$ where acting as sources and load

\begin{tabular}{llrlll}
\hline Hr (h) & $\begin{array}{l}\text { No.of } \\
\text { vehicles } \\
\text { partici- } \\
\text { pated }\end{array}$ & $\begin{array}{l}\text { Ev2G/ } \\
\text { G2Ev out- } \\
\text { put power }\end{array}$ & Hr (h) & $\begin{array}{l}\text { No. of } \\
\text { vehicles } \\
\text { partici- } \\
\text { pated }\end{array}$ & $\begin{array}{l}\text { Ev2G/G2Ev } \\
\text { output power }\end{array}$ \\
\hline 1 & 7204 & -22.96 & 13 & 4714 & 15.03 \\
2 & 5990 & -19.09 & 14 & 5258 & 16.76 \\
3 & 4914 & -15.66 & 15 & 4730 & 15.08 \\
4 & 6954 & -22.16 & 16 & 6718 & 21.43 \\
5 & 7892 & -25.15 & 17 & 11,698 & 37.33 \\
6 & 5498 & -17.52 & 18 & 5158 & 16.27 \\
7 & 4236 & -14.08 & 19 & 5380 & 19.34 \\
8 & 5368 & 28.32 & 20 & 15,918 & 50.73 \\
9 & 9758 & 31.07 & 21 & 7798 & 24.98 \\
10 & 7038 & 23.77 & 22 & 4894 & -15.59 \\
11 & 6438 & 20.56 & 23 & 11,058 & -35.22 \\
12 & 22,932 & 73.10 & 24 & 17,658 & -56.28 \\
\hline
\end{tabular}

vehicles occurs due to parking the vehicle in parking lot and at a home garage about $90-95 \%$ time a day.

Therefore, probability distribution of solar, wind and Electric vehicles is modeled and included in this paper. The probability distribution of solar, wind and electric vehicles for $24 \mathrm{~h}$ are $0.5,0.15$ and 0.5 respectively. The power production of electric vehicle is obtained by considering Average traveling power of Electric Vehicle and Minimum charging time of Electric Vehicle. Thus, the Electric vehicles are operated as loads and storages mainly at night from $10 \mathrm{pm}$ to $7 \mathrm{am}$ and they are operated as sources during working hours from 8 am to $3 \mathrm{pm}$ and during the rest of the time from 4 to $9 \mathrm{pm}$ they are operated as load or sources depending on the system demand and an optimal distribution of 50,000 electric vehicles in $24 \mathrm{~h}$ where they are charged from or discharged to grid and power dispatched from electric vehicles is given in Table 11.

\section{Simulation Results and Discussions}

The proposed methodology is well tested in simulation study for following three cases in order to solve PBUC problem with Emission, Cost and profit is obtained.

Case 1: Ten thermal units.

Case 2: Ten thermal units with Electric Vehicles (EVs).

Case 3: Ten thermal units with Renewable Energy Sources (RESs) and Electric Vehicles (EVs).

Case 1 is described in detail in Sects. 4.1,4.2 and 4.3 and Case 2 and 3 results are provided in this Table 12 The Table compares the operating cost, emission and profit for ten unit system in each scenario. From Table 12, it is observed that in 10 unit $24 \mathrm{~h}$ system, the operating cost and emission are $\$ 5593,367.06$ and 257,391.18 tons, when electric vehicles are considered in smart grid.On the other hand, the operating cost and emissions are $\$ 430,245.3$ and $249,566.88$ tons respectively, when RESs and EVs are integrated in the same system.

Table 12 Result of different cases in terms of emission, cost and profit

\begin{tabular}{|c|c|c|c|c|}
\hline S1. no & Cases & Emission(ton) & Operating Cost (\$) & Profit(\$) \\
\hline 1 & Case 1: Ten thermal units & $260,066.35$ & $533,187.1$ & $137,595.25$ \\
\hline 2 & Case 2: Ten thermal units with Electric Vehicles (EVs) & $257,391.18$ & $559,367.06$ & $171,709.33$ \\
\hline 3 & $\begin{array}{l}\text { Case 3:Ten thermal units with Renewable Energy Sources } \\
\text { (RESs) and Electric Vehicles (EVs) }\end{array}$ & $249,566.88$ & $430,245.3$ & $239,884.00$ \\
\hline
\end{tabular}


The number of electric vehicles connected to the grid or grid to vehicle is not directly proportional to the demand. The scheduling of vehicle depends on non linear price curve, emission curve, constraints and so on.

The optimization method considers these factors and fifty thousand vehicles in grid where Electric vehicles are charged and discharged to or from the grid to reduce cost and emission. The maximum numbers of vehicles are discharged to the grid at peak load of $73.10 \mathrm{MW}$ at $12 \mathrm{PM}$ and maximum charging of electric vehicle take place at 12 to 1 $\mathrm{AM}$ at night.

From the simulation results, it can be observed that The AHP based power generation and reserve allocation for the test system with RESs and EVs energy sources reduces the total operating cost of the thermal units as well as provides high profit to the GENCOs.

From the simulation results, it can be observed that The AHP based power generation and reserve allocation for the test system with Renewable and Electric vehicle energy sources reduces the total operating cost of the thermal units as well as provides high profit to the GENCOs. This is shown in Table 13.
From the Table 13, it is observed that the GENCO decides to shut off Units 5 to units 10 in all committed period and to sell power and reserve less than predicted power demand. This is because, the objective of PBUC is not to minimize operating cost as before but to maximize profit of GENCOs and solar energy is available only at day time from 7 am to $6 \mathrm{pm}$ and wind energy is available most of the time and The Electric vehicles are charged from the grid during $1^{\text {st }}$ to $7^{\text {th }}$ and $22^{\text {nd }}$ to $24^{\text {th }}$ hours. On the other hand, Electric vehicles are discharged to the grid during the $8^{\text {th }}$ to $21^{\text {th }}$ hours.

From the Table 14, it is observed that the total power demand minus the total power of renewable energy and Electric vehicle for each hour is compensated by thermal units. The highest output obtained from renewable energy and electric vehicles is $869.09 \mathrm{MW}$ at $14^{\text {th }}$ hour and the output power generated from thermal power is considered to be lowest.

By Considering the Uncertainty of solar, wind and Electric vehicle, the maximum power is obtained from renewable energy and electric vehicle which reduces the power generation of thermal units thereby it reduces operating cost

Table 13 AHP based optimal power generation and reserve allocation for the ten thermal unit systems with renewable and electric vehicle energy sources

\begin{tabular}{|c|c|c|c|c|c|c|c|c|c|c|c|c|c|c|c|c|c|c|c|c|c|c|c|c|}
\hline \multirow[t]{2}{*}{$\mathrm{Hr}$} & \multicolumn{10}{|c|}{ Generation power (MW) } & \multicolumn{10}{|c|}{ Reserve power (MW) } & \multirow{2}{*}{$\begin{array}{l}\text { Ps } \\
\text { MW }\end{array}$} & \multirow{2}{*}{$\begin{array}{l}\text { Pw } \\
\text { MW }\end{array}$} & \multirow{2}{*}{$\begin{array}{l}\text { Pev } \\
\text { MW }\end{array}$} & \multirow{2}{*}{$\begin{array}{l}\text { Demand } \\
\text { MW }\end{array}$} \\
\hline & P1 & $\mathrm{P} 2$ & P3 & P4 & P5 & P6 & P7 & P8 & P9 & P10 & R1 & $\mathrm{R} 2$ & $\mathrm{R} 3$ & $\mathrm{R} 4$ & R5 & R6 & $\mathrm{R} 7$ & $\mathrm{R} 8$ & R9 & R10 & & & & \\
\hline & 455 & 14.52 & 0 & 0 & 0 & 0 & 0 & 0 & 0 & 0 & 0 & 70 & 0 & 0 & 0 & 0 & 0 & 0 & 0 & 0 & 0 & 23.44 & -22.96 & 722.96 \\
\hline & 455 & 10.80 & 0 & 0 & 0 & 0 & 0 & 0 & 0 & 0 & 0 & 75 & 0 & 0 & 0 & 0 & 0 & 0 & 0 & 0 & 0 & 3.287 & -19.09 & 769.09 \\
\hline & 455 & 410.05 & 0 & 0 & 0 & 0 & 0 & 0 & 0 & 0 & 0 & 45 & 0 & 0 & 0 & 0 & 0 & 0 & 0 & 0 & 0 & 0.61 & -15.66 & 865.66 \\
\hline & 455 & 382.87 & 0 & 130 & 0 & 0 & 0 & 0 & 0 & 0 & 0 & 71 & 0 & 0 & 0 & 0 & 0 & 0 & 0 & 0 & 0 & 3.287 & -22.16 & 972.16 \\
\hline & 455 & 432.03 & 0 & 130 & 0 & 0 & 0 & 0 & 0 & 0 & 0 & 22.96 & 0 & 0 & 0 & 0 & 0 & 0 & 0 & 0 & 0 & 8.117 & -25.15 & 1025.15 \\
\hline 6 & 455 & 01.91 & 130 & 130 & 0 & 0 & 0 & 0 & 0 & 0 & 0 & 53.09 & 0 & 0 & 0 & 0 & 0 & 0 & 0 & 0 & 0 & 0.61 & -17.52 & 1117.5 \\
\hline & 455 & 436.96 & 130 & 130 & 0 & 0 & 0 & 0 & 0 & 0 & 0 & 18.00 & 0 & 0 & 0 & 0 & 0 & 0 & 0 & 0 & 1.51 & 0.61 & -14.08 & 1164.08 \\
\hline & 455 & 326.08 & 130 & 130 & 0 & 0 & 0 & 0 & 0 & 0 & 0 & 120 & 0 & 0 & 0 & 0 & 0 & 0 & 0 & U & 52.95 & 77.68 & 28.32 & 1200 \\
\hline & 455 & 301.83 & 130 & 130 & 0 & 0 & 0 & 0 & 0 & 0 & 0 & 130 & 0 & 0 & 0 & 0 & 0 & 0 & 0 & 0 & 96.69 & 155.4 & 31.07 & 1300 \\
\hline 10 & 455 & 312.13 & 130 & 130 & 0 & 0 & 0 & 0 & 0 & 0 & 0 & 140 & 0 & 0 & 0 & 0 & 0 & 0 & 0 & 0 & 232.5 & 116.6 & 23.77 & 1400 \\
\hline 11 & 455 & 415.14 & 130 & 130 & 0 & 0 & 0 & 0 & 0 & 0 & 0 & 39.86 & 0 & 0 & 0 & 0 & 0 & 0 & 0 & 0 & 154.2 & 145 & 20.56 & 1450 \\
\hline 12 & 455 & 341.10 & 130 & 130 & 0 & 0 & 0 & 0 & 0 & 0 & 0 & 114 & 0 & 0 & 0 & 0 & 0 & 0 & 0 & 0 & 128.9 & 241.9 & 73.10 & 1500 \\
\hline 13 & 445 & 150 & 0 & 0 & 0 & 0 & 0 & 0 & 0 & 0 & 0 & 140 & 0 & 0 & 0 & 0 & 0 & 0 & 0 & 0 & 545.6 & 244 & 15.03 & 1400 \\
\hline 14 & 281 & 150 & 0 & 0 & 0 & 0 & 0 & 0 & 0 & 0 & 0 & 130 & 0 & 0 & 0 & 0 & 0 & 0 & 0 & 0 & 637.7 & 214.6 & 16.76 & 1300 \\
\hline 15 & 365 & 150 & 0 & 0 & 0 & 0 & 0 & 0 & 0 & 0 & 0 & 120 & 0 & 0 & 0 & 0 & 0 & 0 & 0 & 0 & & 22 & 15.08 & 1200 \\
\hline 16 & 369 & 150 & 0 & 0 & 0 & 0 & 0 & 0 & 0 & 0 & 0 & 105 & 0 & 0 & 0 & 0 & 0 & 0 & 0 & 0 & 310.8 & 241.9 & 21.43 & 1050 \\
\hline 17 & 455 & 322.6 & 0 & 0 & 0 & 0 & 0 & 0 & 0 & 0 & 0 & & 0 & 0 & 0 & 0 & 0 & 0 & 0 & 0 & 92.09 & 177.6 & 37.33 & 1000 \\
\hline 18 & 455 & 337.72 & 130 & 130 & 0 & 0 & 0 & 0 & 0 & 0 & 0 & & 0 & 0 & 0 & 0 & 0 & 0 & 0 & 0 & 4.604 & 58.95 & 16.27 & 1100 \\
\hline 19 & 455 & 357.66 & 130 & 130 & 0 & 0 & 0 & 0 & 0 & 0 & 0 & 97.34 & 0 & 0 & 0 & 0 & 0 & 0 & 0 & 0 & 0 & & 19.34 & 1200 \\
\hline 20 & 455 & 455 & 130 & 130 & 0 & 0 & 0 & 0 & 0 & 0 & 0 & 0 & 0 & 0 & 0 & 0 & 0 & 0 & 0 & 0 & 0 & 84.67 & 50.73 & 1400 \\
\hline 21 & 455 & 455 & 130 & 130 & 0 & 0 & 0 & 0 & 0 & 0 & 0 & 0 & 0 & 0 & 0 & 0 & 0 & 0 & 0 & 0 & 0 & 53.41 & 24.98 & 1300 \\
\hline 22 & 455 & 222.98 & 130 & 130 & 0 & 0 & 0 & 0 & 0 & 0 & 0 & 110 & 0 & 0 & 0 & 0 & 0 & 0 & 0 & 0 & 0 & 177.6 & -15.59 & 1115.6 \\
\hline 23 & 455 & 313.92 & 0 & 0 & 0 & 0 & 0 & 0 & 0 & 0 & 0 & 90 & 0 & 0 & 0 & 0 & 0 & 0 & 0 & 0 & 0 & 166.3 & -35.22 & 935.22 \\
\hline 24 & 455 & 234.98 & 0 & 0 & 0 & 0 & 0 & 0 & 0 & 0 & 0 & 80 & 0 & 0 & 0 & 0 & 0 & 0 & 0 & 0 & 0 & 166.3 & -56.28 & 856.28 \\
\hline
\end{tabular}


Table 14 The profit calculation for the standard ten thermal units system with renewable energy sources and Electric vehicles

\begin{tabular}{|c|c|c|c|c|c|c|c|c|c|}
\hline $\mathrm{Hr}$ & $\begin{array}{l}\text { Forecasted } \\
\text { demand } \\
\text { (MW) }\end{array}$ & $\begin{array}{l}\text { Forecast spin- } \\
\text { ning reserve } \\
(\mathrm{MW})\end{array}$ & $\begin{array}{l}\text { Total Power } \\
\text { generated } \\
(\mathrm{MW})\end{array}$ & $\begin{array}{l}\text { Total reserve } \\
\text { allocated } \\
\text { (MW) }\end{array}$ & $\begin{array}{l}\text { MCP for } \\
\text { power }(\$)\end{array}$ & $\begin{array}{l}\text { MCR for } \\
\text { reserve }(\$)\end{array}$ & Total revenue cost $(\$)$ & $\begin{array}{l}\text { Total } \\
\text { operating } \\
\operatorname{cost}(\$)\end{array}$ & Profit (\$) \\
\hline 1 & 700 & 70 & 722.96 & 70 & 21.63 & 32.44 & $17,908.77$ & $13,674.77$ & 4125.00 \\
\hline 2 & 750 & 75 & 769.09 & 75 & 20.59 & 30.88 & $18,151.56$ & $14,943.48$ & 3208.07 \\
\hline 3 & 850 & 85 & 865.66 & 45 & 19.72 & 29.58 & $18,401.91$ & $16,568.04$ & 1836.50 \\
\hline 4 & 950 & 95 & 972.16 & 71 & 21.73 & 32.59 & $23,438.92$ & $19,510.23$ & 3928.69 \\
\hline 5 & 1000 & 100 & 1025.15 & 23 & 21.73 & 32.59 & $23,024.77$ & $19,811.15$ & 3213.62 \\
\hline 6 & 1100 & 110 & 1117.5 & 53.09 & 21.98 & 32.97 & $26,313.46$ & $22,725.32$ & 3588.14 \\
\hline 7 & 1150 & 115 & 1164.08 & 18 & 21.98 & 32.97 & $26,773.39$ & $22,789.38$ & 3984.00 \\
\hline 8 & 1200 & 120 & 1200 & 120 & 21.98 & 32.97 & $30,332.40$ & $20,849.36$ & 9483.03 \\
\hline 9 & 1300 & 130 & 1300 & 130 & 21.98 & 32.97 & $32,860.10$ & $20,426.08$ & $12,434.02$ \\
\hline 10 & 1400 & 140 & 1400 & 140 & 21.98 & 32.97 & $35,387.80$ & $20,605.82$ & $14,781.98$ \\
\hline 11 & 1450 & 145 & 1450 & 39.86 & 21.98 & 32.97 & $33,189.80$ & $22,407.02$ & $10,782.79$ \\
\hline 12 & 1500 & 150 & 1500 & 114 & 21.98 & 32.97 & $36,728.58$ & $21,111.71$ & $15,616.86$ \\
\hline 13 & 1400 & 140 & 1400 & 140 & 23.72 & 35.58 & $38,189.20$ & $11,864.97$ & $26,324.23$ \\
\hline 14 & 1300 & 130 & 1300 & 130 & 23.72 & 35.58 & $35,461.40$ & 9153.26 & $26,308.13$ \\
\hline 15 & 1200 & 120 & 1200 & 120 & 23.72 & 35.58 & $32,733.60$ & $10,539.26$ & $22,194.33$ \\
\hline 16 & 1050 & 105 & 1050 & 105 & 23.72 & 35.58 & $29,150.22$ & $10,995.51$ & $18,154.71$ \\
\hline 17 & 1000 & 100 & 1000 & 100 & 20.26 & 30.4 & $24,056.33$ & $15,036.13$ & 9020.19 \\
\hline 18 & 1100 & 110 & 1100 & 117.28 & 21.98 & 32.97 & $28,402.34$ & $22,167.55$ & 6234.78 \\
\hline 19 & 1200 & 120 & 1200 & 97.34 & 21.98 & 32.97 & $29,585.29$ & $21,407.07$ & 8178.22 \\
\hline 20 & 1400 & 140 & 1400 & 0 & 21.98 & 32.97 & $30,772.02$ & $23,105.73$ & 7666.27 \\
\hline 21 & 1300 & 130 & 1300 & 0 & 21.98 & 32.97 & $28,574.04$ & $23,105.73$ & 5468.27 \\
\hline 22 & 1100 & 110 & 1115.6 & 110 & 21.98 & 32.97 & $28,147.36$ & $19,052.65$ & 9094.7 \\
\hline 23 & 900 & 90 & 935.22 & 90 & 20.35 & 30.52 & $21,778.52$ & $14,886.04$ & 6892.5 \\
\hline 24 & 800 & 80 & 856.28 & 80 & 21.38 & 32.08 & $20,873.78$ & $13,509.02$ & 7364.76 \\
\hline \multicolumn{9}{|c|}{ Total profit for $24 \mathrm{~h}(\$)$} & 239,884 \\
\hline
\end{tabular}

Fig. 5 a Profit obtained from case 3 and $\mathbf{b}$ Profit obtained from different cases
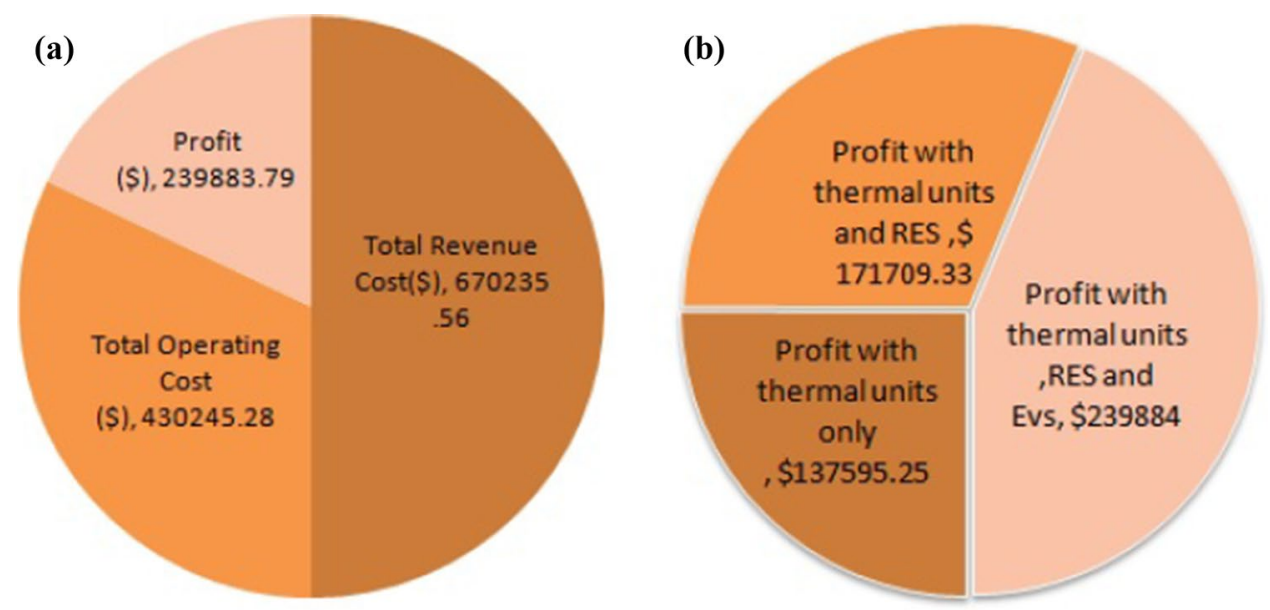

of thermal units and provides profit to GENCOs. The total revenue cost, total operating cost and profit obtained from the ten thermal units with renewable energy sources and electric vehicles is listed in the Table 14.
The TRC, TOC and Profit of GENCOs for case 3 are given in Fig. 5a. Profit obtained from the different cases has been compared in Fig. 5b. From the Fig. 5a it is observed that by optimal scheduling of thermal unit with Renewable 
Energy and Electric Vehicles provides maximum profit to the Generation Companies (GENCOs) and From the Fig. 5b it is also noted that the case 3 as high profit when compared to other two cases.

\section{Conclusion}

In this research work, Unit commitment has been carried out in Cooperative and Competitive environment. A combination of solution methodology i.e. Improved Pre-prepared power demand Table with Analytic Hierarchy Process is proposed for unit commitment problems. It is solved in two stages. Firstly, the statuses of the generating units are obtained by IPPD Table, then Optimal scheduling of committed units is performed by AHP at second stage.

The PBUC approach achieves high profit of GENCOs in a Day ahead scheduling because of its competitive nature when compared to CBUC approach. In addition to that as major contribution, profit based unit commitment is redefined to include the model of market clearing price, multiple distributed resources and Electric vehicles. It is observed that MCP plays a key role in day ahead market to achieve high profit for GENCO.

In this paper, PBUC problem is defined and solved for a smart grid environment where Renewable Energy Sources and Electric Vehicles are integrated with thermal units by proposed methodology. The effects of RES and EV clearly provide low emission, low operating cost and high GENCO profit in a Day ahead market.

\section{Further Work}

This paper intended to solve Profit based unit commitment problem in a smart grid environment with Renewable energy source and Electric Vehicles. However, the emission less and fuel cost free Hydro generation can be considered for the analysis in future. Electric Vehicle batteries have large size and high mass due to which it takes a longer time to charge fully. So it is necessary to focus more on reducing this effort [44]. For future scope of work [45], Battery swapping scenario can be considered in Electric Vehicles. The PBUC problem with system frequency limit constraints can be proposed to facilitate high penetration level of renewable resources and Electric Vehicles. This may be modeled and included in PBUC problem as future work.
Open Access This article is licensed under a Creative Commons Attribution 4.0 International License, which permits use, sharing, adaptation, distribution and reproduction in any medium or format, as long as you give appropriate credit to the original author(s) and the source, provide a link to the Creative Commons licence, and indicate if changes were made. The images or other third party material in this article are included in the article's Creative Commons licence, unless indicated otherwise in a credit line to the material. If material is not included in the article's Creative Commons licence and your intended use is not permitted by statutory regulation or exceeds the permitted use, you will need to obtain permission directly from the copyright holder. To view a copy of this licence, visit http://creativecommons.org/licenses/by/4.0/.

\section{References}

1. Umit A, Saridemir S (2019) A general view to converting fossil fuels to clear energy source by adding nano-particles. Int J Ambient Energy

2. Umit A (2019) Turkey's electricity generation problem and nuclear energy policy. J Energy Sour Part A 41:2281-2298

3. Agbulut U, Saridemir S, Albayrak S (2019) Experimental investigation of combustion, performance and emission characteristics of a diesel engine fuelled with diesel-biodiesel-alcohol blends. J Braz Soc Mech Sci Eng 41(9):389

4. Saridemir S, Agbulut U (2018) A Combustion, performance, vibration and noise characteristics of Cottonseed methylesterdiesel blends fuelled engine. J Biofuels

5. Umit A, Saridemir S (2018) The impacts of ethanol-gasoline blended fuels on the pollutant emissions and performance of a spark. Int J Anal Exp Finite Elem Anal 5(4):50-59

6. Umit A, Bakir H (2019) The investigation on economic and ecological impacts of tendency to electric vehicles instead of internal combustion engines. Duzce Univ J Sci Technol 7(1):25-36

7. Saber AY (2014) Resource scheduling under uncertainty in a smart grid with renewable and plug-in vehicles. IEEE Syst J 6(1):103-109

8. Reddy SS (2019) Optimal operation of Micro grid considering RES, EVs and Demand response. Web of Conference

9. Kum D, Peng H (2013) Optimal energy and catalyst temperature management of plug in hybrid EV for minimum fuel consumption and tail pipe emission. IEEE Trans Control Syst Technol 21(1):14-26

10. Wu J (2017) A power balancing method of distributed generation and $\mathrm{EV}$ charging for minimizing operation cost of distribution system with uncertainties. Energy Sci Eng 5(3):167-179

11. Shantanu (2009) Optimal thermal UC integrated with RES using advanced PSO. IEEE Tran on 2009

12. Liang RH (2007) A fuzzy optimization approach for generation scheduling with wind and solar energy systems. IEEE Trans Power Syst 22(4):1665-1674

13. Yu J, Zhou J, Wu W (2004) Solution of PBUC problem by using multi-agent system. In the proceeding of $5^{\text {th }}$ World Congress on Intelligent Control and Automation pp. 5079-83

14. Sudhaka AV (2017) Profit based unit commitment for GENCOSs using Lagrange relaxation -differential evolution. Int $\mathbf{J}$ Eng Sci Technol 20(2):738-747 
15. Sundaram CS (2017) Tabu search-enhanced ABC algorithm to solve PBUC problem with emission limitations in deregulated electricity market. Int J Metaheuristic 6:107-132

16. Hari D, Kumari S (2017) A hybrid game theory approach to generator bidding in energy and ancillary service markets. Int J Energy Renew Res 7(1):68-79

17. Attaviriyanupap P (2005) New bidding strategy formulation for day -ahead energy and reserve markets based on evolutionary programming. Int J Electr Power Energy Syst 27(3):157-167

18. Bhattacharya A, Roy PK (2012) Solution of multi-objective optimal power flow using gravitation search algorithm. IET Gener Transm Distrib 6(8):751-763

19. Shukla A, Singh SN (2013) Pseudo-inspired PSO for solving unit commitment problem including renewable energy sources. In $5^{\text {th }}$ International conference on power and energy systems

20. Chandram K, Subrahmanyam N (2009) IPPD table and Muller method to solve PBUC problem. J Electr Eng Technol 4(2):159-167

21. Akkaş OP (2018) Application of AHP method for solving the unit commitment problem in a day ahead market. Technol Appl Sci 13(4):310-317

22. Effatnejad R, Gheydi M (2012) AHP method for unit commitment. Int J Tech Phys Probl Eng 4(13):154-159

23. Amudha A, Rajan CCA (2013) Generator scheduling under competitive environment using MMA. Alex Eng J 52(3):337-346

24. Lakshmi K, Vasantharathna S (2014) GENCOs wind-thermal scheduling problem using AIS algorithm. Int J Electr Power Energy Syst 54:112-122

25. Shahidehpour SM, Abdul Rahman KH (1998) Short- term generation scheduling in photo voltaic grid with battery storage. IEEE Trans Power Syst 3(3):1057-1062

26. Reddya KS, Panwar LK (2015) Profit-based conventional resource scheduling with renewable energy penetration. Int J Sustain Energy 36(7):619-636

27. Wu J, Wu Z (2017) A power balancing method of distributed generation and electric vehicle charging for minimizing operation cost of distribution system with uncertainties. Energy Sci Eng 5(3):167-179

28. Saber AY (2011) Plug in vehicles and RES for cost and emission reduction. IEEE Trans Ind Electron 58(4):1229-1238

29. Sheikalishahi B (2012) A new genetic approach for optimizing bidding strategy view point of profit maximization of a GENCOs. Expert Syst Appl

30. Selvi C, Rajan CCA (2009) Multi-area UC with bilateral contract approach in deregulated electricity market. J Electr Eng Technol 4(3):346-352

31. Adline K, Christopher M (2017) PBUC in deregulated electricity markets using a hybrid LR- PSO approach. In Proceeding of sustainable research and innovation RI conference

32. Navdeep (2014) Determination of MCP and optimization of generation scheduling in wind -hydro-thermal Electricity system. Adv Res Electric Electron Eng 1

33. Yamin Y, Shahidehpour SM (2007) A new approach for GENCOs for PBUC in competitive electricity markets considering reserve uncertainty. IEEE Trans Power Syst 29(8):609-616
34. Gross G (1998) Strategic bidding in generation supply markets. IEEE Trans Power Eng

35. Asokan K, Ashok kumar R (2013) A simple approach for optimal generation scheduling to maximize GENCOs profit using IPPD table and $\mathrm{ABC}$ algorithm under deregulated environment. Int J Appl Power Eng 2(3)

36. Nagalakshmi L (2014) PBUC using IPPD table and ABC algorithm. IJAR Electric EIE Eng 3(4)

37. Saaty TL (2008) Decision making with the analytic Hierarchy process. Int J Serv Sci 1(1):83-98

38. Nematbaksh E, Allah R (2017) Generation scheduling of RES under uncertainties in competitive environment. Leonardo Electron J Pract Technol

39. Saleh Y (2018) Net load-constrained UC considering increasing renewable energy penetration levels: impact of generation schedules and operational cost. IJAPE 7

40. Mukhtaruddin R (2015) Optimal hybrid renewable energy design in autonomous system using Iterative-Pareto-Fuzzy technique. Int J Electr Power Energy Syst 64:242-249

41. Shahmoradi A, Kalantar M (2015) Resource scheduling in a smart grid with renewable energy resources and plug -in vehicles by MINLP method. AUT J Electr Eng 47:39-47

42. Osorio G (2015) A new scenario generation-based method to solve the UC problem with high penetration of RES. Int J Electr Power Energy Syst 64:1063-1072

43. Li R (2014) Distribution location marginal pricing for optimal EV charging management. IEEE Trans Power Syst

44. Ahmad F, Alam MS, Shariff SM (2019a) A cost-efficient approach to EV charging station integrated community micro grid: a case study of Indian power market. IEEE Trans Transp Electrification 5(1):200-214

45. Ahmad F, Alam MS, Shariff SM (2019b) A cost-efficient energy management system for battery swapping station. IEEE Syst J 13(4):4355-4364

Publisher's Note Springer Nature remains neutral with regard to jurisdictional claims in published maps and institutional affiliations.

S. F. Syed Vasiyullah received M.E (Power Systems Engineering) in 2006 and B.E (Electrical and Electronics Engineering) in 2004. He is currently pursuing Ph.D part time and working as Assistant Professor in the Department of EEE. He is interested in power system control and operation and Deregulated power systems.

Dr. S. G. Bharathidasan received M.E (Power Systems Engineering) in 2002 and $\mathrm{Ph} . \mathrm{D}$ (Electrical engineering) in 2014 from College of Engineering, Guindy. He is currently working as Associate Professor in the Department of Electrical and Electronics Engineering, Sri Venkateswara College of Engineering, Pennalur, Sriperumbudur. His areas of research in Power System are Micro-Grid and smart grid, FACTS and Renewable Energy Systems and Control System Design. 